\title{
A (des)constituição do ethos do professor pelas vias dos textos midiáticos
}

\author{
Andréia Honório da Cunha
}

Janete Ribeiro Nhoque

\section{Introdução}

Às vezes, diante da figura do professor(a) sinto-me como se estivesse diante de um velho e apagado retrato de família. Com o tempo perderam-se cores, apagaram-se detalhes e traços. A imagem ficou desfigurada, perdeu a viveza, o interesse. Mas um retrato a guardar na gaveta de nossos sonhos perdidos, para revê-lo em tempos de saudade ${ }^{1}$.

Entendemos, como Arroyo, que as imagens e as autoimagens que emergem da atuação do profissional da educação são construídas e levam em consideração um ideal de professor, nem sempre condizente com a realidade ante a dinamicidade dos conflitos que emergem no exercício do cargo/função nos âmbitos sócio-políticos-pedagógicos. Fora o fato de a atuação docente passar por mutações exigidas ou impostas pela conjuntura histórica, que

1 Arroyo, 2001, p. 13. 
acaba por afastar este profissional do ideário construído socialmente sobre "ser professor".

A tensão entre o professor ideal/real se insere como conflito na constituição de seu ethos, o que fortalece, muitas vezes, sentimentos como os destacados por Arroyo e colocam-no num não-lugar sob a perspectiva de ethos aristotélico. Para Türcke,

não ter lugar torna-se uma condição para a percepção. Ter um lugar deixa de ser óbvio quando o aqui e o agora passa a ser multiplicável ao bel-prazer, intercambiável, indiferente. A luta pela percepção converte-se também em uma luta contra tal indiferença. Dar um lugar para um aqui e agora significa dotá-lo de um pertencimento, um contexto e um significado, um sentido. E isso vale para pessoas ${ }^{2}$.

Esta situação de não-lugar que se reverte pelas vias do uso da percepção em sensacionalismo é característica principal da sociedade do espetáculo ${ }^{3}$ na qual vivemos atualmente. E é nesta sociedade que "visa proclamar novos tipos de sociedade ${ }^{4}$ " que se encontra o professor na busca do reconhecimento das qualidades que constituem sua imagem profissional de confiança, a saber, phrónesis, areté e eúnoia. Esta situação é muitas vezes agravada pela forma como as instâncias midiáticas de produção (des)constroem o ethos deste profissional, em especial, nos momentos de manifestações reivindicatórias dos seus direitos profissionais ou civis.

As instâncias midiáticas são aqui entendidas por seu duplo caráter comunicativo: uma instância de produção ${ }^{5}$ e uma instância de recepção ${ }^{6}$. Estas instâncias têm um papel relevante, pois são formadoras de opinião e buscam persuadir seu público a consumir seus respectivos materiais produzidos sem, no entanto, considerar que se trata de fatos reconfigurados a fatos jornalísticos ${ }^{7}$ - cuja natureza não deixa de ser um relato. Os relatos jornalísticos enquanto atos retóricos, isto é, "uma tentativa intencional, criada e trabalhada para superar os desafios em uma dada situação, com um público

2 Türcke, 2014, p. 78.

3 Sociedade do espetáculo, segundo Türcke (2014, p. 10) corresponde também ao termo sociedade da sensação como aquela que vive sob uma torrente de estímulos dos meios de comunicação de massa que competem para fazer parte dessas sensações.

4 Türcke, 2014, p. 11.

5 Instância composta por vários atores com duplo papel: fornecer a informação e impulsionar o desejo de consumir (Charaudeau, 2006).

6 Instância composta pelo público que manifesta seu interesse e/ou prazer em consumir as informações publicadas (Charaudeau, 2006).

7 Gomes, 2003, p. 9. 
específico, a respeito de determinada questão para se alcançar determinado fim $^{8}$ ", afetam o ethos do professor, já que este reflete uma cultura idealizada por um grupo e não as características pessoais dos indivíduos?.

Neste artigo, pautamo-nos em critérios de análise estabelecidos pela retórica aristotélica, seguidos pela Nova Retórica de Perelman e OlbrechtsTyteca, e apresentamos como tema a construção da confiança professor por meio de seu ethos. Partimos da hipótese de que a instância midiática de produção desconsidera, em seu discurso, as qualidades que inspiram confiança nesse profissional. Tal questão é acentuada pela verificação dos argumentos baseados na estrutura do real ${ }^{10}$.

Para tanto, temos como objetivo discutir a (des)constituição do ethos do professor sob o foco dos discursos midiáticos pelas seguintes verificações: a predominância do gênero retórico, seguida pelos argumentos baseados na estrutura do real noticiados a partir das manifestações dos professores da rede estadual de educação de São Paulo durante a greve geral dos professores em 2015.

Este trabalho é de natureza qualitativa quanto à forma de abordagem do problema, bibliográfica no que se refere aos seus procedimentos e exploratória quanto ao seu objetivo ante a tarefa de busca por respostas as seguintes questões: que noções de ethos estão vinculadas à notícia e como essas noções pretendem atuar na constituição da imagem do professor perante a instância de recepção? Quais qualidades aristotélicas do ethos (phrónesis, areté ou eúnoia) são ressaltadas na notícia analisada? Como ela contribui para o fortalecimento ou descrédito do ethos do professor?

Escolhemos como corpus um artigo publicado no jornal Folha de S.Paulo, doravante FSP, em 12 de junho de 2015 - a partir do seguinte critério de seleção: utilização da base de dados da FSP por meio do recurso de busca com filtro das seguintes palavras-chave: professores e greve - no respectivo período da greve iniciada em 13/03/2015 e terminada em 12/06/2015. Na sequência, priorizamos notícias publicadas nos cadernos "Cotidiano" e "Educação". Descartamos as que não tratavam dos movimentos reivindicatórios, assim como as opiniões de colunistas, de leitores do jornal e atos de manifestações de professores de outros estados.

8 Campbell; Huxman; Burkholder, 2015, p. 11

9 Id., 2015.

10 Considerando o real "quer como fatos, quer como verdades, quer como presunções" cf. Perelman e Olbrechts-Tyteca, 2019, p.298. 
Chegamos a cinco artigos e selecionamos o publicado em 12 de junho de 2015 por revelar em seu relato o maior número de atores sociais envolvidos e reiterados em notícias anteriores. Quanto à instância midiática de produção, a FSP foi selecionada por ter divulgação nacional e a maior tiragem impressa de jornais do país, segundo dados de 2018 da Associação Nacional de Jornais (ANJ), sendo assim uma importante instância formadora de opinião.

\section{O ethos do professor, uma imagem desconstituída?}

A retórica busca a persuasão por meio do discurso e, segundo Aristóteles (384-322 a.C.), esta é obtida por três meios: "o primeiro depende do caráter pessoal do orador; o segundo, da influência deste sobre o auditório a uma certa disposição de espírito; e o terceiro, do próprio discurso no que diz respeito ao que demonstra ou parece demonstrar ${ }^{11}$.' O orador tem um papel importante na persuasão do auditório e se efetivará à medida que este for "digno de crédito". Assim, inspirar confiança é seu atributo fundamental.

Estes atributos são denominados ethos - traços de caráter, "jeitos" dirá Barthes ${ }^{12}$, que o orador apresenta para causar boa impressão no auditório. Reboul seguirá um caminho semelhante e denominará este caráter de "etos" afirmando que "etos é um termo moral, 'ético', e que definido como o caráter moral que o orador deve parecer ter, mesmo que não tenha deveras ${ }^{13 \text { ". }}$.

Campbell, Huxman e Burkholder ampliam o uso do termo e consideram que o ethos não se refere apenas ao caráter de um orador, mas "à cultura distinta de um grupo étnico, e o etos do um indivíduo depende do modo como ele reflete as qualidades valorizadas em sua cultura ${ }^{14 "}$. O ethos reflete assim "as características idealizadas por sua cultura ou por seu grupo", em virtude disto, se constitui na relação com o outro e o espaço cultural que se insere.

Quanto às problemáticas propostas, adentramos o assunto a partir da discussão proposta por Oliveira e Cieri que apontam uma mudança no ethos do professor em função de medos constituídos pela contemporaneidade e desmotivação deste profissional decorrente das mudanças legais ocorridas

11 Aristóteles, 2011, p. 45.

12 Barthes, 2001.

13 Reboul, 2000, p. 48.

14 Campbell; Huxman; Burkholder, 2015, p. 212. 
nos últimos anos e a uma "inversão de valores e de autoridade ${ }^{15}$ " na sua atuação profissional.

Para Tardif a profissão docente é atingida por novas demandas da sociedade pós-moderna que acabam por modificar "as missões e os papéis tradicionais da escola em geral e do professor em particular ${ }^{16 "}$. Para o autor, os professores não estão indiferentes a isso, apesar de não terem uma visão do conjunto das mudanças e perceberem e reagirem de diferentes maneiras.

Oliveira e Cieri, ao discutir o ethos do professor diante destas mutações afirmam que este "pode representar caracteres reais de alguém efetivamente honesto, piedoso, religioso, modesto [... ${ }^{17 "}$ e levou-nos a questionar: diante da realidade ora apresentada, este é um ethos ideal para os docentes? Nhoque, ao ouvir os professores de uma escola pública, aponta que uma imagem de professor respeitado e valorizado pela sociedade persegue seus discursos, como emerge do depoimento de uma das participantes da pesquisa:

... o sonho de toda mulher era chegar ao cargo de professora, porque era um cargo equiparado ao cargo de juiz de direito. Nosso salário naquela época era equiparado ao juiz de direito. Não só o respeito, mas como o salário. Então de repente quem tava lá e está aqui hoje vê como se o sonho fosse somente um sonho (profa. Solange - nome fictício) ${ }^{18}$.

Este ethos construído a partir de uma imagem idealizada do passado se quebra diante da realidade da profissão, como afirma outra professora:

... mas na nossa profissão a gente tem que idealizar o passado, né? [...] como professora eu não sei se o que a gente ensina serve para alguma coisa. O que a gente ensina, do jeito que ensinava é desde o começo do século, né? (Profa. Felícia- nome fictício) ${ }^{19}$.

Emerge nas palavras desta professora uma tensão entre ethos idealizado e a realidade vivida que a leva a um questionamento de sua competência profissional. Esta tensão é sentida por muitos professores, como apontam Arroyo $^{20}$, Tardif e Lessard ${ }^{21}$ dentre outros. Imerso neste conflito, o professor é impelido, por si ou pelo meio em que vive e trabalha, a manter um ethos que inspire confiança para persuadir seus alunos, familiares e a própria sociedade de sua competência na formação discente.

\footnotetext{
Oliveira; Cieri, 2015, p. 76.

Tardif, 2008, p. 143.

Oliveira; Cieri, op.cit. p. 77

Nhoque, 2010, p.103-104.

Id., 2010, p. 103-104.

Arroyo, 2001.

Tardif; Lessard, 2008.
} 
O aprofundamento dos estudos referentes às qualidades aristotélicas permite uma observação mais consistente de como o conflito pode ser compreendido em suas bases quanto à busca por soluções àquilo que, na atualidade, se coloca como elemento problematizador na constituição do ethos do professor. Para Barthes estas são as maneiras do orador continuamente dizer ao auditório: "sigam-me (Phrónesis), estimem-me (Areté) e gostem de mim (Eúnoia) ${ }^{22 " .}$ Entretanto, como o ethos é afetado por elementos do contexto retórico, não basta que o professor (sujeito ou coletivo) trabalhe na construção deste ethos se outras instâncias não colaborarem para seu fortalecimento.

Campbell, Huxman e Burkholder apontam que fontes com grande prestígio entre o público tem um efeito significativamente maior na constituição do ethos de um grupo ou um sujeito. Daí a importância de investigarmos a constituição do ethos do professor sob o foco dos discursos midiáticos.

\section{Os textos midiáticos como atos retóricos}

Na retórica, um ato retórico busca convencer e persuadir um determinado auditório, e Reboul ${ }^{23}$ destaca três gêneros discursivos para este fim: o judiciário ao acusar ou defender fatos passados, e nele o auditório atua como juiz; o deliberativo, que aconselha ou desaconselha e aponta para o tempo futuro, neste, o auditório se comporta com uma assembleia; e o epidíctico, que louva ou censura os fatos do presente e o auditório é, assim, seu espectador.

Deste modo, a adesão do interlocutor, do auditório, é fundamental e como destacam Perelman e Olbrechts-Tyteca, "não basta falar ou escrever, cumpre ainda ser ouvido, ser lido ${ }^{24 "}$. Por consequência, o orador, para atingir seus objetivos, busca argumentos que encontre eco naqueles a quem se dirige, assim, para cada auditório haverá um argumento mais ou menos apropriado.

Este é um ponto importante na análise da constituição do ethos do professor sob o foco dos discursos midiáticos. Nesses discursos, espera-se encontrar instância de recepção apta a consumir informações atuais e imparciais reconstituídas sob a forma de notícias. No entanto, sabemos como estudiosos da retórica que a imparcialidade, para além de uma visão positivista, não passa de construções retóricas.

22 Barthes, 2001, p. 78.

23 Reboul, 2000.

24 Perelman; Olbrechts-Tyteca, 2019, p. 19. 
O jornalista lê o fato e o transforma em fato informado por meio de um discurso que envolve seu repertório e sua visão de mundo ${ }^{25}$. Os fatos jornalísticos na condição de atos retóricos estão envoltos sob as perspectivas dos olhares a que se submetem à análise mais acurada. Ideologicamente, não estão livres dos espectros de perspectivas subjetivas de quem as detém sob domínios de poder, controle e acesso.

Analisamos, neste trabalho, os argumentos do artigo da FSP tanto como fato jornalístico quanto ato retórico, pautados, de acordo com Perelman e Olbrechts-Tyteca, na estrutura do real, isto é, naqueles argumentos utilizados como instrumentos de transformação dos fatos em fatos noticiosos subdivididos em relações: de sucessão, que unem um fenômeno a suas consequências ou as suas causas; de coexistência, unem uma pessoa a seus atos, um grupo aos indivíduos que dele fazem parte e, em geral, uma essência a suas manifestações; de hierarquia dupla, aqueles que podem servir de base dos dois argumentos anteriores, tendo em vista a união das relações de sucessão e coexistência como tentativa de sustentação de uma afirmação pelas vias do uso de símbolos.

Destacamos que os argumentos baseados na estrutura do real não se validam pelos aspectos racionais, e sim, nas próprias estruturas do real para estabelecer uma solidariedade entre os juízos admitidos e outros que se procura promover. Tais juízos estão ligados a fatos que se materializam no mundo real sob a forma discursiva e que permitem admitir, promover, ou não, acordos interacionais ${ }^{26}$.

Para Perelman e Olbrechts-Tyteca, os argumentos encontrados no discurso midiático estruturam-se, quanto às ligações de coexistência, apoiados em dois pontos de vistas distintos: filosófico, na união de duas realidades de nível desigual, uma a essência, - no corpus em análise, a greve dos professores - e outra de ordem da manifestação da essência; o retórico, por meio da manifestação relativa às pessoas envolvidas e os atos provenientes delas que se concretizam em suas manifestações, e na relação entre a pessoa e seus atos.

A greve dos professores pelo olhar midiático: a "radicalização" e a fragmentação do grupo em cena

Apresentamos a seguir a análise do artigo "Radicais brecam o fim da greve de professores de São Paulo", de Wálter Nunes, publicada no caderno

25 Ferreira, 2000.

26 Perelman; Olbrechts-Tyteca, 2019. 
Educação do jornal Folha de S.Paulo do dia 12/06/2015, um dia antes da declaração do fim da greve pelos professores.

\section{Radicais brecam fim da greve de professores em São Paulo}

Um grupo de jovens, sem vinculação sindical, que rejeita partidos e que participou das manifestações de junho de 2013 será o principal obstáculo para a direção do Sindicato dos Professores do Ensino Oficial do Estado (Apeoesp), que quer encerrar a greve da categoria na assembleia desta sexta (12).

Os professores vão se reunir às $14 \mathrm{~h}$ no vão-livre do Museu de Artes de São Paulo (Masp) para decidir se continuam ou não com a mais longa paralisação da história da categoria, que nesta sexta completa 89 dias.

Os professores reivindicam, entre outras coisas, reajuste salarial de $75,33 \%$.

O grupo de jovens professores independentes, apelidados de "autonomistas", está acampado na praça da República, no centro da capital, em frente à sede da Secretaria da Educação.

"Queremos que a greve vá até o fim. Depois de 90 dias ainda não conquistamos nada", diz Karina Barros, 35, que dá aulas na cidade de Várzea Paulista (a 54 km de São Paulo) desde 2010.

Karina veio para São Paulo com o marido, também professor da rede estadual, e deixou as duas filhas em Jundiaí aos cuidados de uma irmã. Os dois estão há três dias dormindo em uma barraca. Karina participou das manifestações de junho de 2013.

"Eles (os autonomistas) são muito aguerridos. Não está no horizonte deles acabar com a greve", reconhece o dirigente da Apeoesp Jorge Paz, filiado ao PSOL.

"Tudo aconteceu com a proposta do fim da paralisação. Como a greve estava esvaziada, esses grupos menores ganharam força", diz ele.

A Apeoesp, liderada pela petista Maria Izabel Noronha, a Bebel, quer o fim da greve, mas com um calendário de protestos. Um grupo de militantes do PSOL e do PSTU quer só o fim do movimento. Já os autonomistas não abrem mão da paralisação.

Fernando, que quer ter o sobrenome preservado por medo de represália, diz que não há organização hierárquica entre os autonomistas. 
"A nossa estrutura é horizontal. Decidimos tudo de maneira conjunta", diz o professor de 25 anos, que há cinco dá aulas no extremo sul da capital. Ele não é sindicalizado e nem filiado a partido.

Os autonomistas rejeitam aliança, inclusive com o Partido da Causa Operária (PCO), opositor da direção da Apeoesp e contra o fim da greve.

Richard Araújo, dirigente do sindicato e filiado ao PSTU, resume o impasse. "Nós e os autonomistas temos diferenças em relação ao que é possível a greve conquistar", diz Araújo. "É importante decidir coletivamente o que fazer daqui para a frente."

A presidente da Apeoesp prevê discussões acaloradas. "Os autonomistas não querem negociação. Eles gritam para mim: radicaliza, Bebel!", diz. A autonomista Karina concorda que não será fácil. "Somos a resistência."

O discurso da notícia, pelo uso dos tempos verbais, aponta para o futuro da greve - gênero deliberativo. Tal gênero assume o caráter de valorizar o que parece ser útil ou nocivo a respeito do que discorre, a greve em questão. Ex.: será, quer encerrar, vão se reunir para decidir... Dentre os termos da manchete, destaca-se "radicais", foco da mídia tanto no posicionamento da palavra na manchete como no corpo da notícia.

O discurso em sua estrutura apresenta a predominância dos argumentos baseados na estrutura do real por ligações de coexistência - relação ato-pessoa ${ }^{27}$. $\mathrm{O}$ intento do uso desse argumento aliado à evidência do termo "radicais" foi o de estabelecer uma cisão da coletividade professores contingenciando-a a outros subgrupos em relação de oposição uns para com os outros. Ex. pessoa - ato: radicais - brecam; professores - vão se reunir; os autonomistas - rejeitam; Richard Araújo - resume; a presidente da APEOESP - prevê. Este argumento demonstra interesse em definir os atores em especial os "radicais" em relação aos demais membros da coletividade que assumem compromissos ante as reivindicações gerais da categoria que não mais funciona como uma totalidade coesa em busca de um fim comum.

"Radicais" corresponde a uma escolha lexical que se refere a sujeitos cujas atitudes evidenciam falta de qualidades específicas ao ethos do professor, a saber: figuras desprovidas de solidariedade (eúnoia) e comprometimento com o grupo (areté). Os atos retóricos impostos a esse subgrupo pelo dis-

27 Cf. Perelman; Olbrechts-Tyteca, 2019. 
curso utilizado é brecar - atitude acelerada, desgovernada (manchete) com sentido de "encerrar" (também evidente no primeiro parágrafo) a greve e rejeitar organização sindical e partidária.

Há, entretanto, uma problemática acentuada no terceiro e no quinto parágrafos, o discurso jornalístico rompe com o contrato de informação midiático a respeito do uso entre aspas e parênteses em "autonomistas". A mídia não sabe a proveniência da denominação, foi ela mesma quem apelidou ou não se dispôs a evidenciar o autor? Se Jorge Paz é o autor, por que colocar o termo entre parênteses? Por quais motivos ela adotaria essa postura? Tais escolhas feitas pela mídia desconstituem ainda mais a figura do professor pela areté, pois leva a supor que alguém do grupo tenha feito uso do termo, mas não esclarece quem. A dúvida cria confusões em relação ao contingenciamento da categoria do que esclarecimentos quanto ao fato exposto.

Evidenciamos de igual modo, a utilização de argumentos ad ignorantiam. $O$ jornalista vale-se de apenas um exemplo para tentar explicar a totalidade de um grupo de professores tidos como radicais. O exemplo utilizado pela instância midiática de produção pauta-se em apenas um diálogo com um casal - a professora Karina e seu marido - ambos professores, moradores de Jundiaí que se manifestam há três dias dormindo em uma barraca. Segundo o enunciado, apenas Karina participou das manifestações de 2013. O aprofundamento do argumento ad ignorantiam ocorre nessa única exposição ao interlocutor-leitor, na condição de instância de recepção da informação, como fato que condiz a uma verdade em sua totalidade

$\mathrm{O}$ argumento ad ignorantiam pauta-se, portanto, na falta de profundidade dos argumentos expostos pela instância midiática de produção em supor que apenas um exemplo basta para a aceitação do interlocutor-leitor. Segundo Fiorin ${ }^{28}$, essa postura remete ao reconhecimento do exemplo dado como verdadeiro e suficiente para suprir as dúvidas do interlocutor-leitor a tal ponto de induzi-lo a aceitação e ao não questionamento.

Ademais, a instância midiática de produção não se preocupa em demonstrar as reivindicações da categoria e suas dificuldades em profundidade ao interlocutor-leitor. Ela se detém em determinar a quais partidos políticos vinculam-se os professores e quem ocupa qual função, sobretudo dentro do sindicato. Há, por parte da instância de produção, a preocupação em demonstrar a inserção das bandeiras - argumento por hierarquia dupla via símbolos - defendidas pelo grupo de professores. Por essa postura, ao se 
referir a APEOESP delimita o comando aos termos "liderada pela petista" termos seguidos mais adiante por "um grupo de militantes do PSOL e do PSTU" e seus anseios ante o fim da greve versus "os autonomistas que não abrem mão da paralisação... e rejeitam aliança, inclusive com o PCO".

Notamos a presença de figura de linguagem em "não abrem mão" que determina pela escolha lexical feita pela mídia a noção de radicalização do movimento por parte do subgrupo "autonomistas". "Não abrir mão" corresponde a uma relação de sinédoque do ato de não renunciar, do não ser passível de acordo, do radicalismo a que se sujeita o subgrupo exposto pela notícia - ao professor falta eúnoia em suas ponderações conforme fatos expostos pela mídia. Tais características acentuam a imagem do ethos do professor subdividido em grupos e não categoria unida ante seus propósitos e reivindicações. A instância midiática de produção, assim, colabora para que a imagem da pessoa em análise juntamente a seus atos tenham um aspecto negativo perante os a instância de recepção ${ }^{29}$ que se informa do fato pela FSP.

Outro exemplo de argumento ad ignorantiam fundamentado em apenas uma fala corresponde ao enunciado por Fernando - nome fictício - que teme represálias. Represálias de quem? Do governo que seria um perseguidor dos manifestantes ou dos autonomistas? Não há preocupação da mídia em prezar pelo esclarecimento da origem das represálias.

A instância midiática recorre às vozes da presidente do sindicato versus e da considerada autonomista Karina para mostrar a suposta cisão dos grupos: nós versus eles. Dessa forma, fica evidente a fragmentação dos docentes em diversos subgrupos - radicais, autonomistas, sindicalizados, partidarizados.

Esta fragmentação versa mais para a moção por vias do sensacionalismo, por meio das relações de coexistência, que unem pessoas a seus atos, também por meio da sucessão do evento causa-consequência, permanência ou término da greve; atrelada às bandeiras, como argumentos de hierarquia dupla pelas vias da utilização de símbolos de cada subgrupo.

\section{Considerações finais}

Na notícia analisada a constituição do ethos do professor se dá pela construção de argumentos baseados na estrutura do real tanto por ligações

29 Cf. Perelman; Olbrechts-Tyteca, 2005. 
de coexistência como demonstrado nos exemplos nas correlações entre ato-pessoa; na ligação por sucessão causa-consequência, quanto a greve: permanência ou término e, por fim, aos argumentos de hierarquia dupla com a utilização das bandeiras, como símbolos atrelados ao movimento na condição de instrumentos contingenciados da categoria de professores a subgrupos.

Os atos dos professores aliados aos símbolos, prefigurados em sindicato, partidos políticos a pessoas não-partidarizadas classificadas - radicais e autonomistas - são meios de demonstrar a desunião da categoria. Entendemos que a FSP, na condição de instância midiática de produção vincula a seus interlocutores uma noção de ethos desconstituído de seus valores aristotélicos - phrónesis, areté e eúnoia - pautados nas qualidades que incidem, sobretudo na confiança desse profissional em suas atuações reivindicatórias.

Os professores subdivididos conforme exposto no discurso midiático via argumentos ad ignorantiam avaliam a categoria como sendo composta por inimigos uns dos outros, de modo que as qualidades de confiabilidade que deveriam ser características presentes na figura de um educador são desconstituídas pela ausência de sabedoria em lidar com os confrontos, phrónesis; pela ausência de sinceridade, areté ao não determinar a proveniência da classificação autonomistas e solidariedade para com os colegas, eúnoia.

Nenhuma dessas qualidades são ressaltadas em seus aspectos positivos na notícia analisada, pois o intento maior da mídia parece focar-se naquilo que Türcke ${ }^{30}$ e Tardif e Lessard ${ }^{31}$ assinalaram em seus discursos: a pressão por proclamar novos tipos de sociedade. A comoção via pathos com argumentos ad ignorantiam buscam persuadir o auditório pela emoção, ante os respectivos interesses da mídia - a inversão do lícito que é a manifestação pública em ato ilícito com a demonstração da fragmentação do grupo. A instância midiática ao fazer a transformação do fato em de fato informado não demonstrou preocupação com os atos reivindicatórios da greve proposta pela categoria - posta em segundo plano na manchete e no texto da notícia.

Entendemos que a FSP acentuou a não-razão de confiabilidade, um não-lugar no âmbito da percepção que pode resultar em descrédito naquilo que o professor, enquanto grupo busca em seus movimentos reivindicatórios e não foi exposto no discurso midiático conforme visto no corpus analisado.

30 Türcke, 2014.

31 Tardif e Lessard, 2008. 


\section{Referências}

ASSOCIAÇÃO NACIONAL DE JORNAIS - ANJ. Tiragem impressa dos maiores jornais perde 520 mil exemplares em 3 anos. 31/01/2018. Disponível em $<<$ https://www.anj. org.br/site/menagenda/97-midia-nacional/5251-tiragem-impressa-dos-maiores-jornais-perde520-mil-exemplares-em-3-anos.html $\gg$ Acessado em 20/07/2019.

ARISTÓTELES. Retórica. Trad. Edson Bini. São Paulo: EDIPRO, 2011.

ARROYO, M. 1 G. Ofício de mestre: imagens e auto-imagens. $4^{\mathrm{a}}$ ed. Petrópolis: Vozes, 2001.

BARTHES, R. A aventura semiológica. Trad. Mário Laranjeira. São Paulo: Martins Fontes, 2001.

CAMPBELL, K. K.; HUXMAN, S. S.; e BURKHOLDER, T. R. Atos de retórica: para pensar, falar e escrever criticamente. Trad. Marilene Santana do Santos Garcia. São Paulo: Cengage Learning, 2015.

CHARAUDEAU, Discurso das mídias. Tradução Ângela M.S. Corrêa. São Paulo: Contexto, 2006.

FERREIRA, L. Antonio. Intencionalidade, jornalismo opinativo e leitura. Interface (Botucatu), Botucatu, v. 4, n. 6, p. 187-192, Feb. 2000. Disponível em $<$ http://www. scielo.br/scielo.php?script=sci_arttext\&pid=S1414-32832000000100026\&lng=en\&nrm=iso $>$. Acessado em 15 Aug. 2019. http://dx.doi.org/10.1590/S1414-32832000000100026.

FIORIN, José L. Argumentação. São Paulo: Contexto, 2015.

GOMES, M. R. Poder no jornalismo: discorrer, disciplinar, controlar. São Paulo: Hacker Editores. Edusp, 2003.

NHOQUE, J. R. Processos de formação na escola e a constituição de matrizes pedagógicas coletivas. 2010. 189f. Dissertação-Curso de Mestrado em Educação, Universidade Cidade de São Paulo, São Paulo.

NUNES, W. Radicais brecam o fim da greve de professores em São Paulo. In: Folha de São Paulo, caderno Educação. São Paulo: 12/06/2015. Disponível em $<$ https://www1.folha.uol.com.br/educacao/2015/06/1641151-radicais-brecam-fimda-greve-de-professores-em-sao-paulo.shtml> Acessado em 08/05/2019.

PERELMAN, C.; TYTECA, Lucie O.- Tratado da Argumentação: a nova retórica. Tradução de Maria Ermantina Galvão G. Pereira. $3^{\mathrm{a}}$ ed. $3^{\mathrm{o}}$ tiragem. São Paulo: Martins Fontes, 2019.

REBOUL, O. Introdução à retórica. $1^{\mathrm{a}}$ ed. $2^{\mathrm{a}}$ tiragem. Trad. Ivone Castilho Benedetti. São Paulo: Martins Fontes, 2000.

TARDIF, M. eLESSARD, C. O trabalho docente: elementos para uma teoria da docência como profissão de interações humanas. Trad. João Batista Kreuch. $4^{\mathrm{a}}$ ed. Petrópolis: 2008.

TÜRCKE, C. Sociedade excitada. Tradução de Antonio A.S. Zuin [et.al.]. Campinas. SP: Editora Unicamp, 2014. 
